\title{
Number of Eye Chart Lines Read
}

National Cancer Institute

\section{Source}

National Cancer Institute. Number of Eye Chart Lines Read. NCI Thesaurus. Code C139242.

The number of lines read by the subject during an eye chart assessment. 